\title{
ANALISIS KEMAMPUAN MENDETEKSI EROR KODE PROGRAM MATA KULIAH PEMROGRAMAN BERORIENTASI OBJEK PADA PROGRAM STUDI PENDIDIKAN TEKNOLOGI INFORMASI UNIVERSITAS MUHAMMADIYAH SIDOARJO
}

\author{
Fitria Nur Hasanah \\ Rahmania Sri Untari
}

\begin{abstract}
Abstrak: Tujuan penelitian adalah untuk menganalisis kesulitan mahsiswa dalam mendeteksi error code program dan mengetahui kesulitan yang dihadapi mahasiswa dalam mendeteksi error code program pada mata kuliah Pemrograman Berorientasi Objek (PBO). Metode penelitian yaitu kualitatif tipe studi kasus dengan teknik pengumpulan data wawancara, studi dokumen, dan observasi. Teknik analisis data kasus individu: reduksi, penyajian, kesimpulan sedangkan validasi data dengan triangulasi. Hasil penelitian menunjukkan masalah error coding PBO pada mahasiswa PTI yaitu syntax error dan logical error. Syntax error terjadi ketika mahasiswa kurang teliti saat menyusun code program, kurangnya tanda baca, kesalahan case sensitive, salah keyword. Kedua, mahasiswa tidak paham logika alur program, kurangnya pengetahuan tentang teori pemrograman merupakan penyebab utama mahasiswa hal itu berakibat terjadinya logical error.
\end{abstract}

Kata-kata Kunci: analisis kesalahan, eror kode program, pemrograman berorientasi objek, kemampuan pemrograman

\begin{abstract}
Analysis of Ability To Detect Program Code Error in Object Oriented Programming Course at Study Program of Informatics Education, Muhammadiyah University of Sidoarjo. This research aims to analyze students' difficulties in detecting program code error and to know the difficulties faced by students in detecting program code error in Object Oriented Programming (OOP) course. The research method was a qualitative case study type in which data collection techniques were interview, document study, and observation. The individual case data analysis techniques were reduction, presentation, conclusion, while data validation were triangulation. The result of the research showed the problem of OOP coding error in students of Informatics Education namely syntax error and logical error. Syntax error occured when students were less careful when compiling program code, lack of punctuation, case sensitive errors, and incorrect keywords. In addition, the main causes of logical error were students do not understand the logic of the program flow and lack of knowledge about programming theory.
\end{abstract}

Keywords: error analysis, program code error, object oriented programming, programming capabilities

$\mathrm{P}$ endidikan Tinggi merupakan jenjang pendidikan setelah pendidikan mejuan dari pendidikan tinggi sesuai dengan UU No. 12 Tahun 2012 adalah dihasilnengah (SMK/SMA/MA). Salah satu tukannya lulusan yang menguasai cabang

Fitria Nur Hasanah dan Rahmania Sri Untari adalah Dosen Pendidikan Teknologi Informasi Universitas Muhammadiyah Sidoarjo. Alamat Kampus: Universitas Muhammadiyah Sidoarjo, Jl. Mojopahit No.666 B, Sidowayah, Celep, Sidoarjo 61271.Email: fitrianh@umsida.ac.id. 
ilmu pengetahuan dan atau teknologi untuk memenuhi kepentingan nasional dan peningkatan daya saing bangsa. Perguruan tinggi sebagai salah satu institusi pendidikan merupakan suatu lembaga yang memberikan pelayanan publik, seperti layaknya perusahaan-perusahaan jasa masyarakat pada umumnya. Persaingan antar perguruan tinggi yang semakin ketat membuat perguruan tinggi harus selalu menjaga kualitas pelayanan bagi para stakeholder (para orang tua mahasiswa, dunia usaha, mahasiswa, calon mahasiswa dan alumni) terutama dalam perolehan informasi terkait agar tetap menjadi pilihan utama di masyarakat. Pengelolalan secara profesional akan dapat memberikan kualitas pelayanan yang memuaskan.

Perkembangan teknologi informasi dan komunikasi menjadi bagian dari proses-proses tersebut. Saat ini, banyak perguruan tinggi yang telah menerapkan teknologi informasi dan komunikasi yang berkaitan dengan proses peningkatan mutu pelayanan, namun proses tersebut masih belum terintegrasi, ada juga yang masih dilakukan secara manual. Sedangkan informasi yang diiginkan oleh stakeholer dapat menghasilkan informasi yang lebih bernilai guna, bersifat transparansi dan akuntabilitas terjamin.

Pendidikan Teknologi Informasi (PTI) merupakan salah satu Program Studi di Fakultas Keguruan dan Ilmu Pendidikan (FKIP) Universitas Muhammadiyah Sidoarjo (UMSIDA) yang mempunyai visi mewujudkan Program Studi S1 PTI sebagai pencetak tenaga pendidik yang professional dalam pengembangan bidang Pendidikan Teknologi Informatika dan Komputer yang bermutu tingkat nasional 2025. Selain itu Program Studi PTI mempunyai tujuan mempersiapkan peserta didik untuk bekerja dalam bidang keahlian tertentu. Hal ini sejalan dengan Calhoun dan Finch (1982: 2) yang me- nyatakan bahwa pendidikan kejuruan mencakup dua macam kebutuhan yang harus dipertemukan, yaitu: (1) kebutuhan masyarakat untuk mengisi posisi yang dibutuhkan di lapangan kerja agar sistem ekonomi dapat berjalan secara efisien; dan (2) kebutuhan individual untuk mendapatkan posisi yang memuaskan dalam struktur lapangan kerja. Salah satu keterampilan yang harus dikuasai oleh calon pendidik di bidang teknologi informasi adalah menguasai bahasa pemrograman.

Bahasa pemrograman atau bahasa komputer merupakan instruksi standar untuk memerintah computer (Kadir, 2013). Bahasa pemrograman saat ini semakin banyak dipelajari, hal ini terkait dengan kemajuan zaman yang menjadikan teknologi sebagai hal penting untuk menunjang kemajuan. Salah satu bahasa pemrograman yang harus dikuasai oleh mahasiswa adalah bahasa Pemrograman Berbasis Objek (PBO) dengan menggunakan bahasa java. Pada sebagian besar bahasa pemrograman, sebuah kode program harus dikompilasi (compile) maupun diterjemahkan (inteprete) sehingga dapat dijalankan di dalam sebuah computer (Raharjo, 2012). Compiler di bahasa java mempunyai kemampuan untuk mendeteksi terjadinya error dalam program dengan lebih teliti dibandingkan bahasa pemrograman lain. Java juga memiliki runtime Exception handling untuk membantu mengatasi error dalam penulisan kode program.

Berdasarkan hasil observasi pada mahasiswa PTI semester 3 dalam menyusun code program pada $\mathrm{PBO}$ banyak mahasiswa yang mengalami kesulitan dalam mendeteksi dan menganalisis pesan error. Maka diperlukan analisis untuk mengetahui kesulitan mahasiswa dalam mendeteksi dan menganalisis error program tersebut. Analisis kesalahan ini mengacu pada jenis-jenis kesalahan pada PBO yaitu syntax error, logic error, dan 
runtime error. Menurut Iskandar (2016) terdapat beberapa kesalahan, antara lain kesalahan sistematis dan konsisten terjadi sebabkan oleh tingkat penguasaan materi yang kurang pada mahasiswa, sedangkan kesalahan yang bersifat insidental adalah kesalahan yang bukan merupakan akibat akibat dari rendahnya tingkat pengusaan materi, melainkan oleh sebab lain, misalnya kurang cermat dalam membaca untuk memahami maksud soal.

Salah satu alasan pentingnya pemahaman tentang pesan error bagi mahasiswa dalam menyusun program adalah mahasiswa dapat dengan mudah memperbaiki error pada susunan program ketika mampu menganalisa pesan error. Oleh karena itu mahasiswa memerlukan bantuan secara tepat agar kesulitan yang dihadapi segera teratasi. Agar bantuan yang diberikan dapat berhasil dengan efektif, maka dosen harus memahami letak kesulitan yang dihadapi oleh mahasiswa (Setyono, 2016: 3).

\section{METODE}

Penelitian ini menggunakan pendekatan kualitatif dengan metode studi kasus. Penelitian kualitatif adalah suatu penelitian ilmiah, yang bertujuan untuk memahami fenomena tentang apa yang dialami oleh subjek penelitian misalnya perilaku, persepsi, motivasi, tindakan, dan lain-lain secara holistic dan dengan cara deskripsi dalam bentuk kata-kata pada suatu konteks khusus yang alamiah dengan memanfaatkan berbagai metode ilmiah (Moleong, 2008: 6). Metode studi kasus merupakan strategi penelitian dimana di dalamnya peneliti menyelidiki secara cermat suatu program, peristiwa, aktivitas, proses, atau sekelompok individu. Subjek dalam penelitian kualitatif diambil secara purposive dengan maksud tidak harus mewakili seluruh populasi, sehingga memiliki pengetahuan yang

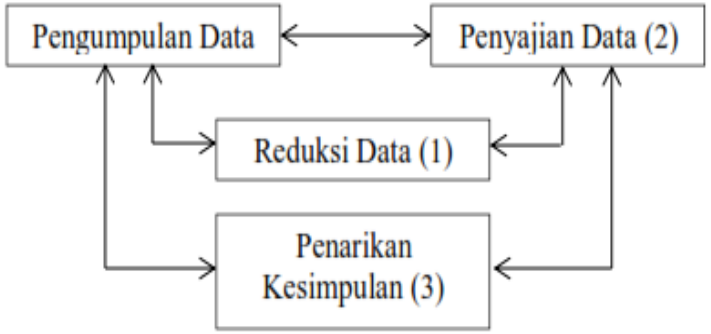

\section{Gambar 1. Alur Analisis Data Kasus Individu}

cukup serta mampu menjelaskan keadaan sebenarnya tentang obyek penelitian. Informan yang akan digunakan dalam penelitian ini adalah mahasiswa PTI semester 3 akademik 2017/2018 yang sedang mengampu Mata Kuliah PBO. Mereka berjumlah 23 mahasiswa. Teknik pengumpulan data yang digunakan oleh peneliti adalah wawancara mendalam observasi (pengamatan), dokumentasi. Pedoman yang dilakukan oleh peneliti untuk melakukan wawancara adalah (1) Kemampuan dan kesulitan mahasiswa dalam menangani error code program; (2) faktor penyebab kesulitan dan kemampuan yang dialami mahasiswa dari dalam diri mahasiswa; (3) faktor penyebab kesulitan dan kemampuan yang dialami mahasiswa dari lingkungan kampus dan teman kuliah; (4) faktor penyebab kesulitan dan kemampuan yang dialami mahasiswa dari lingkungan keluarga. Analisis data yang digunakan adalah analisis data kasus individu, yang ditunjukkan pada Gambar 1.

\section{HASIL}

Temuan penelitian analisis kesulitan mahasiswa dalam mendeteksi dan menganalisis error program diperoleh melalui wawancara, studi dokumen, dan observasi. Temuan penelitian disajikan mengikuti urutan fokus penelitian.

1. Temuan Penelitian Fokus 1 : Masalah error coding PBO

Error coding pada PBO dapat dibagi menjadi 3 jenis, yaitu Syntax Error, Run- 
time Error, dan Logical Error. Jika dilihat dari urutan taraf kesukaran pada saat mahasiswa menganalisis error code program yang terjadi Syntax error ini tergolong yang paling mudah dideteksi, selanjutnya Run-time error dan yang paling susah adalah ketika menjumpai kesalahan jenis logical error. Syntax error yang terjadi pada kode program disebabkan kode yang disusun tidak sesuai dengan aturan/tata cara penulisan yang dimiliki oleh bahasa pemrograman yang digunakan (Suharli, 2005:133). Berdasarkan hasil wawancara pada mahasiswa, syntax error terjadi ketika mahasiswa kurang teliti dalam menyusun code program. Salah satu contoh kesalahan yang dilakukan adalah kurangnya tanda baca dan kesalahan mencantumkan huruf capital, karena pada $\mathrm{PBO}$ merupakan salah satu bahasa pemrograman yang case sensitive, yang artinya penulisan huruf capital maupun huruf kecil mempunyai arti yang berbeda.

2. Temuan Penelitian Fokus 2: Jenis kesalahan yang dilakukan mahasiswa

Prodi PTI saat melakukan coding PBO

Hasil wawancara dan observasi mahasiswa mengetahui jenis-jenis error pada PBO tetapi tidak dapat menganalisis code program ketika mengalami error tersebut sehingga ketika terjadi error pada saat menyusun code program. Mahasiswa memilih untuk menanyakan ke teman sejawat dan ke dosen. Hanya beberapa mahasiswa yang melakukan analisis terhadap error yang terjadi dan ber-

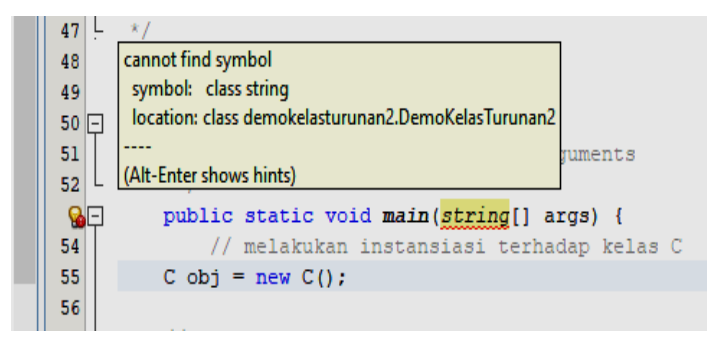

Gambar 2. Syntax Error karena Case Sensitive usaha memperbaiki error tersebut. Berdasarkan hasil observasi, contoh kesalahan yang dilakukan mahasiswa ketika menyusun code program ditunjukkan pada Gambar 2.

Gambar 2 menunjukkan contoh kesalahan code program yang dilakukan oleh mahasiswa dikarenan kesalahan penulisan symbol (case sensitive). Kesalahan tersebut tergolong syntax error. Berdasarkan hasil wawancara, pada saat mahasiswa melakukan penyusunan program dan terjadi error, maka pada program akan menunjukkan pesan kesalahan. Mahasiswa dapat mengetahui dengan cara mengarahkan kursor ke tanda errornya. Beberapa mahasiswa kesulitan pada saat membaca maksud dari pesan tersebut dikarenakan mahasiswa kurang teliti dalam menyusun program. Selain kesalahan penulisan, kesalahan yang dilakukan oleh mahasiswa adalah kesalahan tanda baca, seperti yang ditunjukkan pada Gambar 3.

Gambar 3 menunjukkan contoh kesalahan penulisan code program karena kurang tanda baca, yaitu titik koma (;),

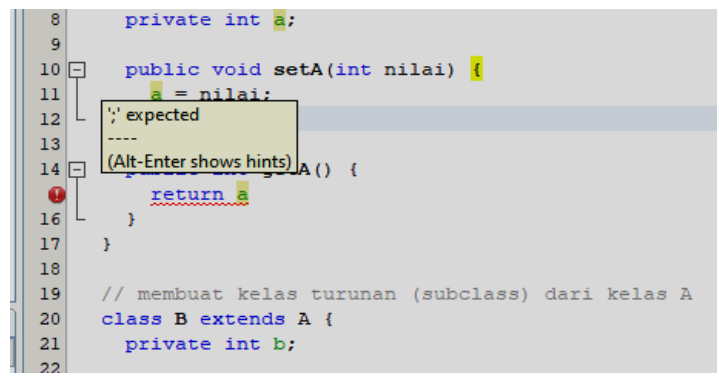

Gambar 3. Syntax Error karena Tanda Baca

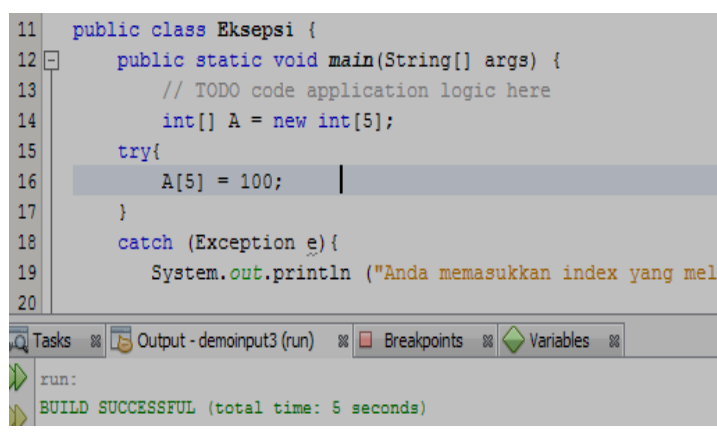

Gambar 4. Logical Error yang Dialami Mahasiswa 
kesalahan ini tergolong pada syntax error. Selain syntax error, jenis kesalahan yang dilakukan oleh mahasiswa adalah logical error, yang ditunjukkan pada Gambar 4.

Gambar 3 menunjukkan bahwa program yang telah dikerjakan oleh mahasiswa tidak mengalami error atau sukses ketika di jalankan, tetapi ketika program di run hasil program tidak keluar. Kesalahan jenis ini merupakan kesalahan logika alur pemrograman, sehingga digolongkan dalam kesalahan logical error. Hal ini dikarenakan mahasiswa kurang memahami konsep struktur program PBO, logika alur pemrograman digunakan sebagai dasar dalam penyusunan program, sehingga ketika mahasiswa belum memahami logika alur berfikir maka akan mengalami kesulitan dalam menyusun code program.

3. Temuan Penelitian Fokus 3 : Kesulitan yang dihadapi mahasiswa prodi PTI dalam mendeteksi dan menganalisis error code pada $\mathrm{PBO}$

Berdasarkan hasil wawancara penjelasan dosen terkait materi error handling pada PBO mudah dipahami tetapi mahasiswa merasa materi error handling pada PBO merupakan mata kuliah yang sulit. Jika mengalami kesulitan pada saat mengerjakan code program mahasiswa melakukan browsing di internet. Sehingga mahasiswa kurang memahami konsep dasar dan logika alur pemrograman. Kurangnya pengetahuan tentang teori pemrograman merupakan predictor yang signifikan dari seorang programmer pemula (Bringula, 2012). Code program mudah dilakukan jika mahasiswa memahami logika alur pemrograman. Logika alur pemrograman dapat dilatih jika mahasiswa memahami konsep pemrograman dan sering melakukan latihan menyusun code program. Dengan referensi yang benar mahasiswa dapat mengetahui lebih jauh bagaimana caranya belajar pemrograman.

\section{PEMBAHASAN}

Dari hasil wawancara dan observasi mahasiswa mengetahui jenis-jenis error pada PBO tetapi tidak dapat menganalisis code program ketika mengalami error tersebut sehingga ketika terjadi error pada saat menyusun code program, mahasiswa memilih untuk menanyakan ke teman sejawat dan ke dosen. Hanya beberapa mahasiswa yang melakukan analisis terhadap error yang terjadi dan berusaha memperbaiki error tersebut, ditunjukkan dari hasil wawancara kepada mahasiswa (P: peneliti, M: mahasiswa) :

$\mathrm{P}$ : Apa yang Anda lakukan ketika terdapat error pada saat penyusunan kode program?

M1 : Pertama saya menanyakan ke teman jika teman sama-sama tidak bisa maka saya bertanya kepada dosen

M2 : Saya mencoba mencari tahu kesalahannya dengan cara mengklik tanda seru dilist program, dengan cara mengecek besar kecilnya huruf, penempatan kode tanda seperti titik koma, dan penempatan kurung kurawal yang salah

Kesalahan pemrograman dapat dikategorikan sebagai syntax error, run time error dan logical error. Syntax error adalah kesalahan karena tata bahasa yang salah. Syntax error sering terdeteksi oleh program yang disebut kompiler, jika bahasa adalah bahasa yang dikompilasi seperti PBO. Run time error adalah kesalahan karena penyalahgunaan konsep pemrograman, meskipun struktur sintaksisnya benar. Run time error tertangkap ketika kode program dikompilasi. Logical error terjadi ketika program tidak menyelesaikan masalah yang dimaksudkan programmer untuk memecahkannya. 
Pesan-pesan kesalahan pada run time error dan logical error ini sulit dimengerti untuk programmer pemula karena pesan hanya menunjukkan kesalahan sintaksis dan di mana itu terjadi (Bhawkar, 2013). Mahasiswa hanya terpaku pada contoh soal praktikum, ketika dosen memberikan soal studi kasus mahasiswa kesulitan menyusun struktur progam, ditunjukkan dari hasil wawancara kepada mahasiswa (P: peneliti, M: mahasiswa) :

$\mathrm{P}$ : Menurut Anda, apakah struktur bahasa PBO mudah dipahami?

M : Tidak mudah dipahami, saya ketika mengerjakan latihan bisa memahami karena ada contohnya akan tetapi ketika membuat suatu program sendiri tanpa ada panduan saya bingung dengan struktur progamnya harus bagaimana dan coding yang dipakai seperti apa

Sebagian besar kesalahan yang dilakukan oleh mahasiswa adalah karena mahasiswa kurang teliti dalam menyusun code program, seperti kurang titik koma (;) yang digunakan untuk mengakhiri program, salah penulisan case sensitive program. Hal ini selaras dengan penelitian dari Mow (2012) yang menjelaskan bahwa sebagian besar kesalahan sintaksis sederhana adalah karena kecerobohan siswa. Hal lainnya yang harus dilakukan oleh mahasiswa adalah mencari sumber referensi dari mana saja mengenai pemrograman, namun harus hati-hati jika diambil dari internet karena ada beberapa referensi yang justru melenceng dari pemahaman sebagaimana mestinya. $70 \%$ mahasiswa PTI menggunakan referensi dari internet ketika mengalami kesulitan memahami dan mengerjakan PBO. Hal tersebut ditunjukkan dari hasil wawancara kepada mahasiswa (P: peneliti, M: mahasiswa):

P : Apakah Anda mempunyai buku atau referensi untuk mata kuliah PBO (ebook, modul, dll)?
M1 : Tidak punya bu, biasanya browsing dari internet

Kemajuan teknologi informasi dan internet saat ini melimpah, sehingga orang bebas memasukkan informasi di dunia maya tanpa batas (Kurnianingsih, 2017). Hal tersebut mengakibatkan perubahan perilaku pada mahasiswa dalam memanfaatkan dan mengelola informasi. Dengan keberagaman tipe dan bentuk informasi seharusnya mahasiswa lebih selektif dan mampu memaksimalkan penggunaan hasil kemajuan teknologi informasi.

Code program mudah dilakukan jika mahasiswa memahami logika alur pemrograman. Logika alur pemrograman dapat dilatih jika mahasiswa memahami konsep pemrograman dan sering melakukan latihan menyusun code program. Hai ini selaras dengan yang disampaikan oleh Bringula (2012) yang memaparkan bahwa kurangnya pengetahuan tentang teori pemrograman merupakan predictor yang signifikan dari seorang programmer pemula. Pentingnya pemahaman tentang pesan error bagi mahasiswa dalam menyusun program adalah mahasiswa dapat dengan mudah memperbaiki error pada susunan program ketika mampu menganalisa pesan error. Oleh karena itu mahasiswa memerlukan bantuan secara tepat agar kesulitan yang dihadapi segera teratasi. Agar bantuan yang diberikan dapat berhasil dengan efektif, maka mahasiswa harus memahami letak kesulitan yang dihadapi. Berdasarkan hasil wawancara yang dilakukan, factor yang menyebabkan mahasiswa mengalami kesulitan menganalisis error code pada PBO adalah factor internal dari mahasiswa, ditunjukkan dari hasil wawancara kepada mahasiswa (P: peneliti, M: mahasiswa):

P : Apakah Anda sering melakukan latihan di rumah untuk melakukan coding berbasis java? 
M : Tidak, hanya ketika mau mengerjakan tugas saja.

$\mathrm{P}$ : Seberapa sering Anda meluangkan waktu untuk mempelajari mata kuliah PBO?

M : Kadang-kadang, atau pada saat tugas akan ditagih dosen.

Beberapa siswa sering mendapatkan kesalahan kompilasi, seperti sintaks-kesalahan karena salah ketik. Oleh karena itu mereka merasa bahwa pemrograman terlalu sulit, yang secara tidak langsung mengurangi kepercayaan diri mereka. Masalah yang paling penting adalah siswa tidak dapat membaca pesan kesalahan secara efektif dari kompilator.

\section{SIMPULAN DAN SARAN}

Berdasarkan hasil penelitian yang telah dilakukan oleh peneliti maka masalah error coding PBO disebabkan oleh pemahaman awal mahasiswa tentang konsep logika alur pemrograman dan kemampuan alalisis code program masih lemah karena kurangnya literasi, mahasiswa perlu diberikan pembiasaan literasi agar konsep pemrograman bisa dikuasai. Kedua, mahasiswa hanya terpaku pada contoh soal praktikum, ketika dosen memberikan soal studi kasus mahasiswa kesulitan menyusun struktur progam. Ketiga, mahasiswa kurang teliti dalam menyusun code program, ditunjukkan ketika mengalami syntax error pada saat penyusunan mahasiswa tidak dapat menganalisis notice kesalahan. Keempat, kurang aktifnya mahasiswa dalam bertanya ketika mahasiswa kurang memahami materi. Kelima, mahasiswa jarang melakukan latihan menyusun kode program di waktu luangnya, sehingga kemampuan menyusun dan menganalisis code program kurang berkembang.

Dosen disarankan agar mengembangkan bahan ajar dan modul yang sesuai dengan karakteristik mahasiswa untuk perkuliahan PBO yang nantinya dapat membantu mahasiswa dalam menangani kesalahan-kesalahan pada saat menyusun code program dan membantu siswa memahami mata kuliah PBO. Mahasiswa seharusnya aktif selama proses perkuliahan di kelas, terutama jika terkait dengan pemahaman mahasiswa pada materi perkuliahan. Ketika mahasiswa melakukan penyusunan code program sebaiknya dilakukan dengan teliti dan memperhatikan kaedah penyusunan $\mathrm{PBO}$, serta ketika terjadi error pada saat melakukan penyusunan code program, sebaiknya mahasiswa melakukan analisis terhadap error yang terjadi sesuai dengan penjelasan dari dosen terkait penanganan error code program. Bagi peneliti selanjutnya, disarankan untuk melakukan penelitian lebih lanjut mengenai penanganan kesulitan mahasiswa dalam menangani error code program serta mengembangkan modul praktikum dan bahan ajar yang disesuaikan dengan karakteristik mahasiswa

\section{DAFTAR RUJUKAN}

Bhawkar, A. 2013. Analysis of Errors- A Support System for Teacher to Analyze the Error Occurring to a Novice Programmer. International Journal of Computer Science and Network. 2 (5): 37-40. (Online), (https://arxiv. org, diakses 21 Maret 2018).

Bringula, R.P. 2012. Predictors of Errors of Novice Java Programmers. World Journal of Education. 2 (1): 3-15. (Online), (https://eric.ed.gov/ diakses 21 Maret 2018)

Iskandar, R.S.F. \& Andriyani, R. 2016. Analisis Kesalahan Pembuktian Matematis Mahasiswa pada Matakuliah Analisis Real. Proseding Seminar Nasional Pendidikan Matematika dengan tema " Pengembangan 4C's dalam Pembelajaran Matematika: sebuah Tantangan dalam Pengembangan Kurikulum Matematika”. 
Tesis tidak diterbitkan Pascasarjana Universitas Negeri Malang.

Kadir, A. \& Triwahyuni, T.C. 2013. Pengantar Teknologi Informasi. Yogyakarta: Andi.

Moleong, L.J. 2008. Metodologi Penelitian Kualitatif. Bandung: PT. Remaja Rosdakarya.

Mow, I.T.C. 2012. Analyses of Student Programming Error In Java Programming Course. Journal of Emerging Trends in Computing and Information Science. 3 (5): 739-749. (Online), (https://pdfs.semanticscholar.org/, diakses 21 Maret 2018).
Raharjo, B., Heryanto, I. \& Haryono, A. 2012. Mudah Belajar Java. Bandung: Informatika.

Setyono, A. 2016. Analisis Kesulitan Siswa Memecahkan Masalah Fisika Berbentuk Grafik dengan tes Diagnostik. Skripsi tidak diterbitkan. Semarang: UNNES. 